$3 \cdot 2 / 1000$ was high for Italy and other countries in Europe, suggesting that coeliac disease in childhood may be more common than has previously been recognised. However, of 11 subclinical cases of coeliac disease reported after screening, nine had recognisable clinical features of this disorder such as recurrent apthous stomatitis, iron deficiency anaemia, recurrent diarrhoea, or short stature. The study raises important questions about the value of population screening for coeliac disease and whether patients would benefit by being identified at a symptomless stage. ${ }^{18}$ Children with coeliac disease are considered to have a lifelong intolerance to dietary gluten, yet only a third of adults with this disorder gave a history of coeliac disease in childhood. ${ }^{19}$ Screening would not only identify children with unrecognised disease but also detect disease in adults, in whom delayed diagnosis or misdiagnosis is common, because a chronic state of ill health is often accepted as normal.

\section{Screening families for coeliac disease}

AGA testing in serum has been successfully used to screen relatives of patients with coeliac disease, ${ }^{20}$ in whom there is a strong association with class II HLA genes. As most of the affected relatives are symptom free, they would normally be reluctant to undergo intestinal biopsy. Yet malignancy and cancer deaths ${ }^{21}$ occur more frequently in first degree relatives and a gluten free diet would have a protective effect on them. ${ }^{22}$

\section{Conclusions}

Measurement of AGA, AEA, and ARA antibodies in serum are valuable in screening children for coeliac disease, but jejunal biopsy remains the 'gold standard' for making the diagnosis. The arguments for population screening may increase as these tests become more reliable. The indications for treating asymptomatic patients with coeliac disease with a gluten free diet need to be established. Some adolescents with the disease do not keep to their gluten free diet, yet have no symptoms. Less contentious are the arguments for using a gluten free diet to treat patients with symptomatic coeliac disease; in these cases there is often a remarkable improvement in mood and general wellbeing within a few days of starting treatment. ${ }^{23}$
Somerset Children's Research Unit,

D N CHALLACOMBE

Taunton and Somerset Hospital,

Musgrove Park, Taunton,

Somerset TA1 5DA

1 Meeuwisse GW. Diagnostic criteria in coeliac disease: report of a round table discussion. Acta Paediatr Scand 1970; 59: 461-3.

2 Anderson CM, Forbes D, Gracey M. Coeliac disease. In: Gracey M, Burke V, eds. Pediatric gastroenterology and hepatology. Boston: Blackwell, 1993: 403-25.

3 Auricchio S, Greco L, Troncone R. Gluten-sensitive enteropathy in childhood. Pediatr Clin North Am 1988; 35: 157-87.

4 Holmes GKT. Long-term health risks for unrecognised coeliac patients. In: Auricchio S, Visakorpi JK, eds. Common food intolerances 1: epidemiology of coeliac disease. Basel: Karger, 1992: 105-18.

5 Walker-Smith JA, Guandalini S, Schmitz J, Schmerling D, Visakorpi JK. Revised criteria for diagnosis of coeliac disease. Arch Dis Child 1990; 65: 909-11.

6 Challacombe DN, Wheeler EE. The use of a stathmokinetic technique with crypt microdissection to estimate the crypt cell production rate in cultured explants of the duodenal mucosa in celiac disease. Hepatogastroenterology 1992; 39 (suppl II): 154-7.

7 Rolles CJ, Kendall MJ, Nutter S, Anderson CM. One-hour blood-xylose screening-test for coeliac disease in infants and young children. Lancet 1973; ii: $1043-5$.

$8 \mathrm{McNeish}$ AS, Willoughby MLN. Whole blood folate as a screening test for coeliac disease in childhood. Lancet 1969; i: 442-3.

9 Challacombe DN, Goodall M, Gaze H, Brown GA. Urinary 5-hydroxyindoleacetic acid in 8-hour collections as an aid in diagnosis of coeliac disease. Arch Dis Child 1975; 50: 779-81.

10 Juby L, Rothwell AJ, Axon ATR. Lactulose/mannitol test: an ideal screening test for coeliac disease. Gastroenterology 1989; 96: 79-85.

11 Husby S, Foged N, Host A, Svehag S-E. Passage of dietary antigens into the blood of children with coeliac disease. Quantification and size distribution of absorbed antigens. Gut 1987; 28: 1062-72.

12 Troncone R, Ferguson A. Anti-gliadin antibodies. I Pediatr Gastroenterol Nutr 1991; 12: 150-8.

13 Unsworth DJ, Brown DL. Serological screening suggests that adult coeliac disease is underdiagnosed in the UK and increases the incidence by up to 12\%. Gut 1994; 35: 61-4.

14 Burgin-Wolff A, Gaze H, Hadziselimovic F, et al. Antigliadin and antiendomysium antibody determination for coeliac disease. Arch Dis Child 1991; 66: 941-7.

15 Rossi TM, Kumar V, Lerner A, Heitlinger LA, Tucker N, Fisher J. Relationship of endomysial antibodies to jejunal mucosal pathology: specificity towards both symptomatic and asymptomatic celiacs. $\mathcal{I}$ Pediatr Gastroenterol Nutr 1988; 7: 858-63.

16 Ladinser B, Rossipal E, Pittschieler K. Endomysium antibodies in coeliac disease: an improved method. Gut 1994; 35: 776-8.

17 Catassi C, Ratsch I-M, Fabiani E, et al. Coeliac disease in the year 2000: exploring the iceberg. Lancet 1994; 343: 200-3.

18 Challacombe DN. When is a coeliac? Lancet 1994; 343: 188.

19 Barry RE, Baker P, Read AE. The clinical presentation. Clinical Gastroenterology 1974; 3: 55-69.

20 Corazza G, Valentini $R$, Frisoni $M$, et al. Gliadin immune reactivity is associated with overt and latent enteropathy in relatives of celiac patients. Gastroenterology 1991; 103: 1517-22.

21 Stokes PL, Prior P, Sorahan TM, McWalter RJ, Waterhouse JAH, Cooke WT. Malignancy in relatives of patients with coeliac disease. British Journal of Preventive and Social Medicine 1976; 30: 12-21.

22 Holmes GKT, Prior P, Lane MR, Pope D, Allan RN. Malignancy in coeliac disease-effect of a gluten-free diet. Gut $1989 ; 30$; 333-8.

23 Challacombe DN, Wheeler EE. Are the changes of mood in children with coeliac disease due to abnormal serotonin metabolism? Nutr Health 1987; 5: 145-52.

\title{
Microalbuminuria and nephropathy in insulin dependent diabetes mellitus
}

Diabetic nephropathy is an important cause of morbidity and mortality in insulin dependent diabetes mellitus (IDDM). The patients at greatest risk of developing diabetic renal disease are those who develop IDDM in childhood. ${ }^{1}$ Longitudinal epidemiological studies have shown that individuals with IDDM have a cumulative incidence of nephropathy of $30-50 \%$ after 40 years of disease. ${ }^{23}$ Therefore in Britain alone it is estimated that 750000 people have diabetic renal disease with approximately 600 patients entering end stage renal failure each year. As a contributor to the adult programmes from end stage renal disease, diabetes exceeds all forms of glomerulonephritis added together and as a single cause it is rivalled only by hypertension. As the development of renal complications poses a serious threat to the life and wellbeing of the diabetic patient, its prevention or amelioration by treatment is an important goal. Microalbuminuria is presently felt to be the most reliable indicator of adverse renal and cardiovascular events in diabetics, ${ }^{4}$ therefore screening for its presence is an important part of the management of these patients.

\section{Factors predisposing to diabetic nephropathy}

The results of the Diabetes Control and Complications Trial Research Group have confirmed that poor glycaemic control is a major risk factor for the development of diabetic 
nephropathy. ${ }^{5}$ However, not all patients with poor glycaemic control develop nephropathy suggesting that only a subset of diabetic patients are at risk from this complication. ${ }^{67}$ This has prompted a search by many investigators for other possible positive predictive factors. Those that have been identified include age at diagnosis and diabetes duration, ${ }^{8}$ relative insulin resistance, ${ }^{9}$ increased sodiumlithium countertransport, ${ }^{10}$ smoking, ${ }^{11}$ family history of diabetic nephropathy, 12 and a family history of hypertension. ${ }^{13}$ The most recent studies, however, seem to indicate that hypertension is in itself not a risk factor for initiating nephropathy, but develops as a consequence of it. ${ }^{14} 15$

\section{Pathogenesis}

Although the clinical course of diabetic nephropathy has been well described, ${ }^{14}$ its pathogenetic mechanisms are less well understood. A number of related hypotheses have been proposed which involved a combination of haemodynamic and metabolic factors and are based on the abnormalities observed under experimental conditions in isolated tissues and animal models or early in the course of disease in man.

The central features of diabetic vascular complications are an abnormal leakage of proteins from the circulation and progressive luminal constriction of the blood vessels. ${ }^{1617}$ Abnormalities of capillary basement membranes including the glomerular basement membrane have been extensively studied in patients with IDDM as has mesangial composition and size. Glomerular basement membrane consists primarily of type IV collagen, hyaluronic acid, the protoglycan heparan sulphate and laminin, the major noncollagenous protein. ${ }^{18}$ Heparan sulphate is synthesised by the endothelial cells and is highly negatively changed. ${ }^{19}$ Decreased levels have been found in the glomerular basement membrane in both animals and humans with diabetes. $^{20}$ This decrease is apparently not due to a failure of production of heparan sulphate, but because less of it is incorporated into the glomerular basement membrane. ${ }^{21}$ Incorporation is dependent on the ligand binding properties of laminin. This binding affinity is reduced by the increased non-enzymatic glycosylation of laminin found in diabetes. ${ }^{22}$ As charge is an important factor in the integrity of the endothelium and glomerular basement membrane, decreased heparan sulphate could contribute to the increased vascular permeabiiity and increased glomerular filtration rate (GFR) of negatively charged proteins such as albumin observed in diabetes. ${ }^{23}$ Extravasation of plasma proteins into the mesangium might contribute to the mesangial expansion and progressive glomerular damage which results in glomerulosclerosis. The glomerular filtration surface then becomes reduced eventually leading to a fall in GFR. ${ }^{24-26}$

As early as the onset of diabetes an increase in GFR can be detected. It decreases toward a more normal value with better metabolic control. ${ }^{27}$ Hyperfiltration may return later in the course of the disease and has been found to be predictive of the development of later nephropathy by some investigators, ${ }^{28}$ but challenged by others. ${ }^{29}$ Hyperfiltration is due to a combination of increased renal blood flow, increased transglomerular hydraulic pressure, and increased filtration area ${ }^{30}$ and has been centrally implicated in the pathogenesis of nephropathy by Hosteller et al. ${ }^{31}$ They provide evidence that hyperfiltration results in glomerular damage and proteinuria. Glomerulosclerosis ensues with accompanying loss of renal function.

\section{Classification of diabetic nephropathy}

In 1982, Viberti et al reported that patients with IDDM who were at risk of clinical nephropathy could be identified at an early stage by detecting small increases in urinary albumin excretion (UAE), a phenomenon named microalbuminuria. Its presence characterises the stage of incipient nephropathy. ${ }^{32}$ Over the last decade, several studies have been performed to investigate the predictive power of microalbuminuria for clinical proteinuria, chronic renal failure, morbidity, and mortality in IDDM. After completing a 23 year follow up study, Messent $e t$ al concluded that microalbuminuria was presently the most reliable indicator available to the clinician of adverse renal and cardiovascular events in diabetic patients. ${ }^{4}$ By general consensus, microalbuminuria is defined in the adult as a UAE of $20-200 \mu \mathrm{g} / \mathrm{min}$ (or $30-300 \mathrm{mg} / 24$ hours) in a timed overnight collection in two out of three urines collected consecutively preferably within a six month period. ${ }^{33}$ This supranormal quantity of urinary albumin escapes detection by indicator dye binding tests such as those used in reagent strips like Albustix (Bayer). ${ }^{34}$ Above this level, Albustix testing becomes positive and the patient is then classified as having overt nephropathy. It is during this phase that there is persistent proteinuria, a fall in GFR and deterioration in renal function. Without treatment, the outlook for these patients is poor with $50 \%$ dying within seven years. ${ }^{35}$

\section{Screening for microalbuminuria}

Measurement of UAE in timed urine samples remains the gold standard for the definition of microalbuminuria. ${ }^{36}$ However, as timed and measured urine collections can be difficult, especially in children, this precludes their use as a routine screening procedure. Attempts have therefore been made to relate either the albumin concentration or albumin:creatine ratio (UA/UC) to UAE in random or first morning urine specimens. Using random urine samples, Gatling and colleagues reported only weak correlations of urinary albumin concentration and UA/UC with albumin excretion rate in a timed overnight collection $(r=0.45$ and 0.43 respectively). However, if the albumin concentration or UA/UC was measured in an early morning urine sample, the correlation with the overnight albumin excretion rate was stronger $\left(0.90\right.$ and 0.91 respectively). ${ }^{37}$ Taking a UA/UC value of $3.5 \mathrm{mg} / \mathrm{mmol}$ in an early morning sample to predict an overnight albumin excretion rate of 30 $\mu \mathrm{g} / \mathrm{min}$ gave a sensitivity of between $88-100 \%$ and specificity of $95-99 \%$. The most reliable method of screening for microalbuminuria is therefore felt to be the measurement of UA/UC in an early morning (first void) urine sample. The use of albumin concentration or UA/UC in a random urine sample is not recommended because of unacceptably low sensitivity and specificity in predicting microalbuminuria. ${ }^{37} 38$

There remains some debate as to whether all diabetic patients should be screened for microalbuminuria. Screening should certainly focus on those with an early age at onset of diabetes, duration of diabetes greater than five years, hypertension, persistent hyperglycaemia (glycated haemoglobin $>11 \%$ ) or any evidence of retinopathy or neuropathy.

\section{Microalbuminuria in children}

A general consensus has been reached for the quantitative definition of microalbuminuria in adults, but this has not been the case in paediatrics. In the few studies that have investigated albumin excretion in the urine of normal children, the upper $95 \%$ tolerance limit has been used as the lower limit of definition for microalbuminuria. ${ }^{39-42}$ In these early studies, the values reported lay between 7 and $12.2 \mu \mathrm{g} / \mathrm{min} / 1.73 \mathrm{~m}^{2}$. It can be seen that these values lie 
below the defined predictive levels for microalbuminuria quoted in adult studies. The significance of having an albumin excretion rate above normal but below $20 \mu \mathrm{g} / \mathrm{min}$ is not known as no long term predictive work following on from these initial studies has been reported. A more recent study of albumin excretion rate in children has used 20 $\mu \mathrm{g} / \mathrm{min}$ as the lower limit of definition of microalbuminuria. ${ }^{43}$

The prevalence of microalbuminuria in children with diabetes is reported to be between $7-20 \%$, the exact value depending upon the cut off point for defining microalbuminuria. ${ }^{41-45}$ The prevalence increases with the age of the population under study. This is probably explained not only by the increased disease duration in the older children, but also because of the observation that children seem to be relatively protected from developing the complications of diabetes before the onset of puberty, thus calling into question the role of growth hormone and sex steroids in their development. ${ }^{404246}$

\section{Following up microalbuminuria}

The upper reference limit for microalbuminuria is quoted as an early morning UA/UC $>1.5 \mathrm{mg} / \mathrm{mmol} .{ }^{47}$ Repeated testing of diabetic patients for microalbuminuria reveals that many are only intermittently positive. ${ }^{48}$ If microalbuminuria is detected on three successive occasions, it is considered persistent and approximately $80 \%$ of these patients will go on to develop overt nephropathy. This progression has been reported to take between 13 and 18 years, although it may occur faster in some patients. ${ }^{35} 49$

It is recommended that patients with $\mathrm{UA} / \mathrm{UC}$ values between $1.5-3.5 \mathrm{mg} / \mathrm{mmol}$ should have their UA/UC values repeated annually. Patients with UA/UC values $>3.5 \mathrm{mg} / \mathrm{mmol}$ should have timed overnight urine collections performed to confirm the diagnosis of microalbuminuria and UA/UC ratios measured 4-6 monthly. A value of UA/UC $>3.5 \mathrm{mg} / \mathrm{mmol}$ obtained on repeated testing should identify those patients who would benefit from specific treatment. Close monitoring (every three months) of the response of UAE to treatment is important.

\section{Potential treatment for the prevention of diabetic nephropathy}

The controversy about whether improvement in glycaemic control would substantially reduce the risk of development and progression of diabetic retinopathy, nephropathy, and neuropathy finally ended with the publication of the Diabetes Control and Complications Trial Report in 1993.5 In a group of highly motivated volunteers aged 13-39 years it convincingly demonstrated that intensified glycaemic control would reduce the risk of complications in all patients with diabetes. The patients receiving intensive treatment attended clinic monthly, had frequent reviews by telephone, and 24 hour access to medical advice. The glycated haemoglobin level was measured monthly and the patients monitored their own blood glucose concentration four times daily. Insulin was administered in three or more injections per day and the dose was altered according to the frequently monitored blood glucose values. Achieving this tight control (that is, near normoglycaemia) in young children would neither be possible not desirable because of the risks of severe hypoglycaemia. Improving glycaemic control in our adolescent diabetics requires a great deal of effort on the part of both the patients and those who care for them. This would require a substantial increase in the medical and paramedical input into their day to day care with huge financial implications to the NHS. Although every effort should go into improving glycaemic control, the benefits against the risks have to be balanced and the treatment strategy must be tailored for the individual patient.

Apart from improving blood sugar control there are other potentially beneficial treatment modalities. The effects of angiotensin converting enzyme (ACE) inhibition have been found to be beneficial both in overt and incipient nephropathy with and without hypertension. .0-52 The $^{50}$ results of the European Microalbuminuria Captopril Study Group reported that captopril treatment significantly impeded progression to clinical proteinuria and prevented the increase in albumin excretion rate in nonhypertensive adult diabetics with persistent microalbuminuria. ${ }^{52}$ In the only study reporting the use of ACE inhibitors in normotensive diabetic children with microalbuminuria, Cook et al found that captopril was effective in decreasing albumin excretion rate. ${ }^{53}$ Data from an animal model of diabetes suggest that ACE inhibition may directly reduce intraglomerular pressure by selective vasodilatation of the efferent arteriole and, in doing so, reduces proteinuria. ${ }^{54} \mathrm{ACE}$ inhibitors may also have an effect on glomerular hypertrophy and mesangial matrix formation and therefore they may have other benefits to the diabetic kidney independent of their antihypertensive effect. ${ }^{55} 56$ This makes this group of drugs the ones of choice in treating hypertension in diabetes.

In addition to the above therapeutic measures, a reduction in dietary protein has been shown to have a beneficial effect in diabetes with renal disease as a high protein intake is known to increase the GFR and increase intraglomerular pressure. ${ }^{5758}$ However, protein restricted diets are unpleasant to take and compliance in diabetic children would be a major problem.

\section{Conclusion}

As microalbuminuria has been established as a powerful marker of both early nephropathy and premature cardiovascular disease in diabetes mellitus, screening for microalbuminuria in children and adolescents with diabetes is recommended. The first step in treatment of a persistently elevated UAVUC value in an early morning urine sample should aim at achieving better metabolic control if possible. Although the short term use of ACE inhibitor drugs in normotensive children has been shown to be beneficial in one study, the outcomes of further studies are required before their use can be recommended for all diabetic children with microalbuminuria. In children with diabetes and hypertension they should be the antihypertensives of choice. As the risk of nephropathy and premature death is a long term one, many years will elapse before the full implications of screening for microalbuminuria and intervention programmes are realised.

University of Leeds School of Medicine,

FIONA M CAMPBELL

Division of Paediatrics and Child Health,

Level 5, Clinical Sciences Building,

St fames's University Hospital,

Leeds LS9 7TF

1 Parving $\mathrm{HH}$, Hommel $\mathrm{H}$, Mathiesen $\mathrm{E}$, et al. Prevalence of microalbuminuria arterial hypertension, retinopathy and neuropathy in patients with insulin dependent diabetes. $B M \mathcal{F}$ 1988; 296: 156-60

2 Anderson AR, Christiansen JS, Andersen JK, Kreiner S, Deckert $T$. Diabetic nephropathy in type I (insulin dependent) diabetes: an epidemiDiabetic nephropathy in type I (insulin dependent

3 Krolewski AS, Warram JH, Christlieb AR, Busik EJ, Kahn CR. The changing natural history of nephropathy in type I diabetes. Am f Med 1985; 78: ing natural

4 Messent JWC, Elliott TG, Hill RD, Jarrett RJ, Keen H, Viberti GC. Prognostic significance of microalbuminuria in insulin dependent diabetes mellitus. A 23 year follow-up study. Kidney Int 1992; 41: 836-9. 
5 The Diabetes Control and Complications Trial Research Group. The effects of intensive treatment of diabetes on the development and progresEngl f Med 1993; 329: 977-85.

6 Wang PH, Lau J, Chalmers TC. Meta analysis of effects of intensive blood glucose control on late complications of type I diabetes. Lancet 1993; 341: 1306-9.

7 Reichard P, Nilsson B-Y, Rosenquist U. The effect of long-term intensified insulin treatment on the development of microvascular complications of diabetes mellitus. $N$ Engl f Med 1993; 329: 304-9.

8 Coonrod BA, Lloyd CE, Ellis D, et al. Predictors of microalbuminuria in individuals with IDDM. Pitsburgh epidemiology of diabetes complication study. Diabetes Care 1993; 16: 1376-83.

9 Yip J, Matlock MB, Morcutti A, et al. Insulin resistance in insulin dependent diabetic patients with microalbuminuria. Lancet 1993; 342: 883-7.

10 Houtman PN, Campbell FM, Shah V, Grant DB, Dunger DB, Dillon MJ. Sodium-lithium countertransport in children with diabetes and their families. Arch Dis Child 1995; 72: 133-6.

11 Chase HP, Garg SK, Marshall G, et al. Cigarette smoking increases the risk of albuminuria among subjects with type I diabetes. $\Im A M A 1991 ; 265$ : 614-7.

12 Borch-Johnsen K, Norgaard K, Hommel E, et al. Is diabetic nephropathy an inherited complications? Kidney Int 1992; 41: 719-22.

13 Viberti GG, Keen H, Wiseman MJ. Raised arterial pressure in parents of proteinuric insulin dependent diabetics. $B M F$ 1987; 295: 515-7.

14 Norgaard K, Feldt-Rasmussen B, Borch Johnsen K, et al. Prevalence of hypertension in type I (insulin-dependent) diabetes mellitus. Diabetologia 1990; 33: 407-10.

15 Mogensen CE, Osterby R, Hansen KW, Damsgaard EM. Blood pressure elevation versus abnormal albuminuria in the genesis and prediction of renal disease in diabetes. Diabetes Care 1992; 9: 1191-204

16 Mogensen CE. Microalbuminuria as a predictor of clinical diabetic nephropathy. Kidney Int 1987; 31: 673-89.

17 Wallow IHL, Ergerman RL. Permeability and patency of retinal blood vessels in experimental diabetes. Invest Ophthalmol Vis Sci 1977; 16: 447-61.

18 Osertby R, Gundersen HJG, Nyberg G, Avrell $M$. Advanced diabetic glomerulopathy: quantitative structural characterisation of non-occluded glomerulopathy: quantitative structural

19 Beisswenger PJ, Spiro RG. Studies on the human glomerular basement membrane. Composition, nature of the carbohydrate units and chemical membrane. Composition, nature of the carbohydrate units

20 Kanwar YS, Farquhar MG. Anionic sites in the glomerular basement membrane. f Cell Biol 1979; 81: 137-53.

21 Shimomura H, Spiro RG. Studies on macromolecular components of human glomerular basement membrane and alterations in diabetes. Diabetes 1987; 36: 374-81.

22 Klein DJ, Brown DM, Oegema TR. Glomerular proteoglycans in diabetes. Diabetes 1986; 35: 1130-41.

23 Tarsio JF, Reger LA, Furcht LT. Molecular mechanisms in basement membrane complications in diabetes. Diabetes 1988; 37: 532-9.

24 Cotran RS, Rennke HG. Anionic sites and the mechanisms of proteinuria. $N$ Engl f Med 1983; 309: 1050-2.

$25 \mathrm{Klahr} \mathrm{S,} \mathrm{Schreiner} \mathrm{G,} \mathrm{Ichikawa} \mathrm{I.} \mathrm{The} \mathrm{progression} \mathrm{of} \mathrm{renal} \mathrm{disease.} N \mathrm{Engl}$ f Med 1988; 309: 1050-2.

26 Steffes MW, Osterby R, Chavers B, Mauer SM. Mesangial expansion as a central mechanism for loss of kidney function in diabetic patients. Diabetes 1989; 38: 1077-81.

27 Sandahl-Christensen J, Gammelgaard J, Frandsen M, Parving H-H. Increased kidney size, glomerular filtration rate and plasma flow in shortterm insulin-dependent diabetics. Diabetologia 1981; 20: 451-6.

28 Rudberg S, Persson B, Dahlquist G. Increased glomerular filtration as a predictor of diabetic nephrology: an 8 year prospective study. Kidney In 1992; 41: 822-8.

29 Jones SL, Wiseman MJ, Viberti GC. Glomerular hyperfiltration as a risk factor for diabetic nephropathy; five year report of a prospective study. Diabetologia 1991; 34: 59-60.

30 Christiansen JS. Glomerular hyperfiltration in diabetes mellitus. Diabet Med 1985; 2: 235-9.

31 Hostetter TH, Troy J, Brenner BM. Glomerular haemodynamics in experimental diabetes mellitus. Kidney Int 1981; 19: 410-5.

32 Viberti GC, Hill R, Jarret RJ, Argyropoulos A, Mahmud Y, Keen H. Microalbuminuria as a predictor of clinical nephropathy in insulin depenMicroalbuminuria as a predictor of clinical neph

33 Mogensen CE, Chachati A, Christensen CK, et al. Microalbuminuria: an early marker of renal involvement in diabetes. Uraemia Investigation 1985-6; 9: 85-95.

34 Viberti GC, Keen $\mathrm{H}$. The patterns of proteinuria in diabetes mellitus Diabetes 1984; 33: 686-92.

35 Deckert T, Feldt-Rasmussen B, Borch-Johnsen K, et al. Natural history of diabetic complications: early detection and progression. Diabet Med 1991; 8 (symposium): S33-7.

36 Marshall SM. Screening for microalbuminuria: which measurement? Diabet Med 1991; 8: 706-11.

37 Gatling W, Knight C, Mullee MA, Hill RD. Microalbuminuria in diabetes: a population study of the prevalence and an assessment of three screening tests. Diabet Med 1988; 5: 343-7.

38 Gatling W, Knight C, Hill RD. Screening for early diabetic nephropathy: which sample to detect microalbuminuria. Diabet Med 1985; 2: 451-5.

39 Davies AG, Postlethwaite RJ, Price DA, Burn JL, Houlton CA, Fielding BA. Urinary albumin excretion in school children. Arch Dis Child 1984, 59: 625-30.

40 Rowe DJF, Hayward M, Bagg H, Betts PB. Effects of glycaemic control and duration of diabetes on overnight albumin excretion in diabetic children. BMF 1984; 289: 957-9.

41 Gibb DM, Dunger D, Levin M, et al. Early markers of the renal complications of children with insulin-dependent diabetes mellitus. Arch Dis Child 1989; 64: 984-91.

42 Mathieson ER, Saurbrey N, Hommel E, Parving H-H. Prevalence of microalbuminuria in children with insulin dependent diabetes. Acta Diabetol 1986; 29: 640-3.

43 Rudberg S, Ullman E, Dahlquist G. Relationship between early metabolic control and the development of microalbuminuria - a longititudinal study in children with type I (insulin-dependent) diabetes mellitus. Diabetologia 1993; 36: 1309-14.

44 Chuimello G, Bognetti E, Meschi F, et al. Early diagnosis of subclinica complications in insulin-dependent diabetic children and adolescents. $\mathcal{f}$ Endocrinol Invest 1989; 12: 101-4.

45 Davies AG, Price DA, Postlethwaite RJ, et al. Renal function in diabetes mellitus. Arch Dis Child 1985; 60: 299-304.

46 Williamson JR, Chang $\mathrm{K}$, Tilton $\mathrm{CP}$, et al. Increased vascular permeability in spontaneously diabetic $\mathrm{BB} / \mathrm{W}$ rats and rats with mild versus severe streptozocin-induced diabetes: prevention by aldose reductase inhibitors streptozocin-induced diabetes: prevention

47 Wats GT, Bennett JE, Rowe DJ, et al. Assessment of immunochemical methods for determining low concentrations of urinary albumin in urine. methods for determining low

48 Watts GF, Kubal C, Chinn S. Longterm variation of urinary albumin excretion in insulin dependent diabetes mellitus: some practical recommendations for monitoring microalbuminuria. Diabetes Res Clin Pract 1990; 9 169-77.

49 Cooper ME, Frauman A, O'Brien RC, et al. Progression of proteinuria in type 1 and type 2 diabetes. Diabet Med 1988; 5: 361-8.

50 Parving H-H, Hommel E, Smidt UM. Protection of kidney function and decrease in albuminuria by captopril in insulin dependent diabetics with nephropathy. $B M F$ 1988; 297: 1086-91.

51 Parving H-H, Hommel E, Nielsen MD, Giese J. Effect of captopril on blood pressure and kidney function in normotensive insulin dependent diabetics with nephropathy. BMF 1989; 299: 533-6.

52 Viberti GC, Mogensen CE, Groop LC, Pauls JF. Effect of captopril on progression to clinical proteinuria in patients with insulin dependent diabetes gression to clinical proteinuria in patients with insulin dependent diabetes Captopril Study Group. $\mathfrak{F A M A}$ 1994; 271: 275-9.

53 Cook J, Daneman D, Spino $M$, et al. Angiotensin converting enzyme inhibitor therapy to decrease microalbuminuria in normotensive children with insulin dependent diabetes mellitus. $\mathcal{F}$ Pediatr 1990; 117: 39-45.

54 Zatz R, Dunn BR, Meyer TW, Anderson S, Rennke HG, Brenner BM Prevention of diabetic glomerulopathy by pharmacological amelioration of glomerular capillary hypertension. f Clin Invest 1986; 77: 1925-30.

55 Mogensen CE. Management of diabetic renal involvement and disease. Lancet 1988; i: 867-70.

56 Marre M, Chatellier G, Leblanc M, et al. Prevention of diabetic nephropathy with enalapril in normotensive diabetics with microalbuminuria. $B M \mathcal{F}$ 1988; 297: 1092-5.

57 Brenner BM, Meyer TW, Hostetter TH. Dietary protein intake and the progressive nature of kidney disease. N Engl f Med 1982; 307: 652 .

58 Brouhard BH, La Grone L. Effects of dietary protein restriction on functional renal reserve in diabetic nephropathy. Am f Med 1990; 89: 427-31. 